\title{
Systematic review of the prevalence of current smoking among hospitalized COVID-19 patients in China: could nicotine be a therapeutic option?: Comment
}

\author{
Dinesh Vijay Rajput ${ }^{1}$ (D)
}

Received: 14 May 2020 / Accepted: 1 June 2020 / Published online: 8 June 2020

(c) Società Italiana di Medicina Interna (SIMI) 2020

\begin{abstract}
This is a comment on the low prevalence of smokers in hospitalized COVID-19 patients, citing the possible role of squamous cell metaplasia, which is commonly associated with smokers.
\end{abstract}

Keywords Squamous cell metaplasia $\cdot$ COVID-19 infection $\cdot$ SARS-CoV-2 infection · Smokers · SARS-CoV 2003 infection

\section{Dear Editor,}

Konstantinos Farsalinos, Anastasia Barbouni, and Raymond Niaura have observed a consistent low prevalence of smoking among SARS-CoV-2-infected patients in China and the USA, almost $1 / 4$ th of the observed prevalence. The authors have credited this beneficial effect of smoking to nicotine, via its immunomodulatory effects and complex interactions with the renin-angiotensin system [1].

However, the effect or interactions of squamous cell metaplasia (SQM) as a possible deterrent to SARS-CoV-2 infection appears to be overlooked. Previous studies have noted that SQM is almost always present in smokers [2-4]. Alteration of the cell type, as seen in metaplasias, is known to alter its cell surface characteristics; in this case the squamous metaplasia might not allow the binding of SARS$\mathrm{CoV}-2$ virus as seen in normal pseudostratified epithelium, which might be one of the reasons of low prevalence of COVID-19 infection in smokers. Further, many studies have detailed about pathologic changes observed in SQM, such as

Dinesh Vijay Rajput

drrajput13@gmail.com

1 Department of Oral Pathology and Microbiology, YCMM and RDF's Dental College and Hospital, 166/1, Vadgaon Gupta, Shendi MIDC, Ahmednagar, Maharashtra 414003, India
- Replacement of single layer thick polarized, pseudostratified epithelium with multi-layered non-polarized, squamous epithelium [2].

- Significant reduction of ciliated cells and proliferation of mucous cells $[2,4]$.

- Acquisition of granular cell layer-like properties, as noted by expression of larger and a greater number of desmosomes [4], presence of keratohyalin-like granules [3], and expression of involucrin, especially in the superficial layers of SQM area [4].

Based on these findings, it can be construed that SARSCoV-2 is unable to infect SQM areas-due to presence of cross-linked envelope (effect of keratohyalin-like granules [3], involucrin), which bars the entry of virus and related degeneration of nucleus [3], preventing the viral replication. Furthermore, as the superficial cells in SQM lose contact with basal lamina [4], it might reduce the cytokine-induced reactions, probably needing less hospitalization in smokers, as observed by the authors. In addition, due to its similar genetic makeup, this association should also be seen in SARS-CoV (2003) infection; however because of lesser number of reported cases and fewer studies elaborating on smoking statistics, it seems difficult to correlate. However, recently, Wrapp et al. [5] have shown that SARS-CoV-2 has 10- to 20-fold more affinity for angiotensin converting enzyme 2 (ACE2) receptors than SARS-CoV (2003). This fact indirectly proves the lesser incidence of SARS-CoV 2 infection in smokers, which could be attributed to squamous cell metaplasia, as cell surface characteristics are known to 
alter in it, probably including the ACE 2 receptors as well. It could also explain differences, if any, between the prevalence of SARS CoV 2003 infection and SARS CoV-2 Infection in smokers. Considering these above-mentioned facts, the probable link between squamous cell metaplasia in smokers and prevalence of SARS-CoV-2 infection should be assessed scientifically.

\section{Compliance with ethical standards}

Conflict of interest The authors declare that they have no conflict of interest.

Human and animal rights Not applicable.

Informed consent Not applicable.

\section{References}

1. Farsalinos K, Barbouni A, Niaura R (2020) Systematic review of the prevalence of current smoking among hospitalized COVID-19 patients in China: could nicotine be a therapeutic option? Intern Emerg Med. https://doi.org/10.1007/s11739-020-02355-7

2. Auerbach O, Gere B, Forman JB, Petrick TG, Smolin HJ, Muesham GE, Kassouny DY, Stout AP (1957) Changes in the bronchial epithelium in relation to smoking and cancer of the lung. A report of progress. NEJM 256(3):97-104

3. Klein-Szanto AJP, Topping DC, Heckman CA, Nettesheim P (1980) Ultrastructural characteristics of carcinogen-induced dysplastic changes in tracheal epithelium. Am J Pathol 98:83-100

4. Trump BF, McDowell EM, Glavin F, Barrett LA, Becci PJ, Achürch W, Kaiser HE, Harris CC (1978) The respiratory epithelium III. Histogenesis of epidermoid metaplasia and carcinoma in situ in the human. J Natl Cancer Inst 61:563-575

5. Wrapp D, Wang N, Corbett KS, Goldsmith JA, Hsieh C-L, Abiona O, Graham BS, McLellan JS (2020) Cryo-EM structure of the 2019-nCoV spike in the prefusion conformation. bioRxiv preprint. https://doi.org/10.1101/2020.02.11.944462

Publisher's Note Springer Nature remains neutral with regard to jurisdictional claims in published maps and institutional affiliations. 